\title{
Community Views and Attitudes for Waste Management Improvement in a Higher Education Institute: Case Study
}

\author{
S. Wijetunga
}

Dept. of Agricultural Engineering, Faculty of Agriculture, University of Ruhuna, Mapalana, Kamburupitiya, Sri Lanka

Tel: (94) 41229 2200; Fax: (94) 41229 2384; E-mail: swije2001@yahoo.com

\begin{abstract}
The safe disposal technologies for waste is utmost important. Before planning and implementation of waste management systems, the views and attitudes of community (stakeholders) are very important. In this study, it was attempted to gather the views of community in the Faculty of Agriculture, University of Ruhuna on environmental issues and waste management, and evaluate them for the improvement of waste management system towards sustainability. Questionnaire survey and informal discussions were carried out to gather information on waste management. Randomly selected sample was taken. Informal discussions were also held. Gathered data were analyzed through simple descriptive methods. Most of the respondents (96\%) know that environmental degradation is a serious problem due to improper disposal of solid wastes. Over $90 \%$ of people know the waste management system practiced in the Faculty and its demerits. Eighty nine percents of people like to support and cooperate, activity for the waste management programs implemented in the Faculty and they also (69\%) know that the cooperation is essential for the management of wastes. The people in the Faculty like to cooperate and participate for a proper waste management system. Therefore, their involvement should be encouraged for the development and implementation of waste management system in the Faculty.
\end{abstract}

KEYWORDS: Waste Management, Solid waste, Waste disposal

\section{Introduction}

The generation of different types of waste in various places such as industries, institutions, residences, is common in the world. In Sri Lanka, waste collection and disposal has become a serious problem in recent years. With development, people are more likely to live in urban areas, so, every day waste generation is increasing. Therefore, more efforts have to be taken to tackle the waste disposal problem. Wastes in urban areas (garbage) are composed of various matters such as degradable organics (plant and animal matters), non degradable organics (plastics, polythene), various metals, glasses, rubber materials, textiles and papers. Major 
components of municipal solid waste in Sri Lanka are organics in nature which include food waste and garden wastes and they are degradable in nature (Visvanathan, 2006 and Perera, 2003). At the same time these different wastes comes from various places such as institutions (government or private owned), factories, residences, etc.

Even though there are different available methods for waste management, the universal waste management system for all the countries has not yet been developed. Therefore, it is essential to have sustainable waste management strategies for various locations in a particular country. It has been estimated that over 6400 tons/day of solid waste are generated in Sri Lanka. Solid waste generation potential in Sri Lanka ranges between $0.25-0.5 \mathrm{~kg} / \mathrm{day} /$ person. The most common practice in almost all municipalities in Sri Lanka are open burning, land filling (not technical) and open dumping of wastes. These methods are not considered as environmental friendly since they create serious environmental problems. About $85 \%$ of collected waste in Sri Lanka is subjected to open dumping (Visvanathan, 2006).

Wastes can generally be managed through reduction, reuse, recycling and final disposal in an environmentally friendly manner (Forbes et al., 2001). These methods can be used in micro level (in homes, institutions such as schools, offices, etc) or macro level (Urban councils or municipal councils). The technology or management system should be economically viable, socially acceptable and environmentally effective for the sustainability of technology or management system (Forbes et al, 2001). Before the introduction of a new waste management system for any institute, the prevailing waste management system of the institute should be properly evaluated.

In this study, it was attempted to gather the views of community in the Faculty of Agriculture, University of Ruhuna on environmental issues and waste management and evaluate them for the improvement of waste management system towards sustainability.

\section{Materials and Methods}

The study was conducted in the Faculty of Agriculture, University of Ruhuna. The Faculty comprises of different sections such as hostels of students, staff quarters, canteen, departments, administrations complex, and a research farm with an area of 65 ha. About 1500 have frequently been housed and visited by the Faculty of Agriculture including undergraduate students ( 600), staffs $(\sim 200)$ and people of $(\sim 500)$ the area visit for various purposes such as buying farm goods and fourteen families live in staff quarters.

A questionnaire survey and informal discussions were carried out to gather information on waste management in the Faculty of Agriculture. Identification of 
merits and demerits were also addressed with special reference to community attitudes towards waste management. Further, methodology of present waste collection system, frequency of collection, problems associated with collection system, the fate of collected waste and the effectiveness of the waste collection system were focused in this survey. A randomly selected sample was taken, covering all possible parties such as academic staff, non academic staff, and students and cleaning service personals amounting to a sample size of 70 for the survey. Informal discussions were also held with the individuals (randomly) in the Faculty of Agriculture covering all parties in the faculty. Gathered data were analyzed through simple descriptive methods using Microsoft spread sheet software.

\section{Results and Discussion}

\section{Education}

In the survey and informal discussions, waste collection system, frequency of collection, problems associated with collection system, fate of collected waste and the effectiveness of the waste collection system were evaluated. Majority (51\%) of the sample were male, while $31 \%$ of them were postgraduate qualified persons. The higher numbers of educated people in the respondents are basically due to the nature of institute. As far as others were concerned, $26 \%$ and $30 \%$ of them were graduates and undergraduates. There were only $3 \%$ in the sample having only primary education. The implementation of effective waste management system to an institute would be easy where higher numbers of educated people work and reside.

\section{Waste Disposal Technologies}

Almost all (96\%) of the respondents agreed that environmental degradation is a serious problem due to the mismanagement of waste while $3 \%$ said that it's a problem but not serious and $1 \%$ did not have idea about relationship between environmental pollution and waste management. As far as the industrial development and environment issues are concerned, $63 \%$ of the respondents said that there should be balance on development and environment issues, while $17 \%$ respondents argued that the development should consider over environment issues. Fourteen percent of respondents expressed that more concern should be paid to environmental issues rather than development. Over $91 \%$ of the respondents were aware about, at least, the waste management in the Faculty. When they were offered a multiple choices of management options regarding waste, majority (70\%) of them preferred to have recycling (Figure 1). 


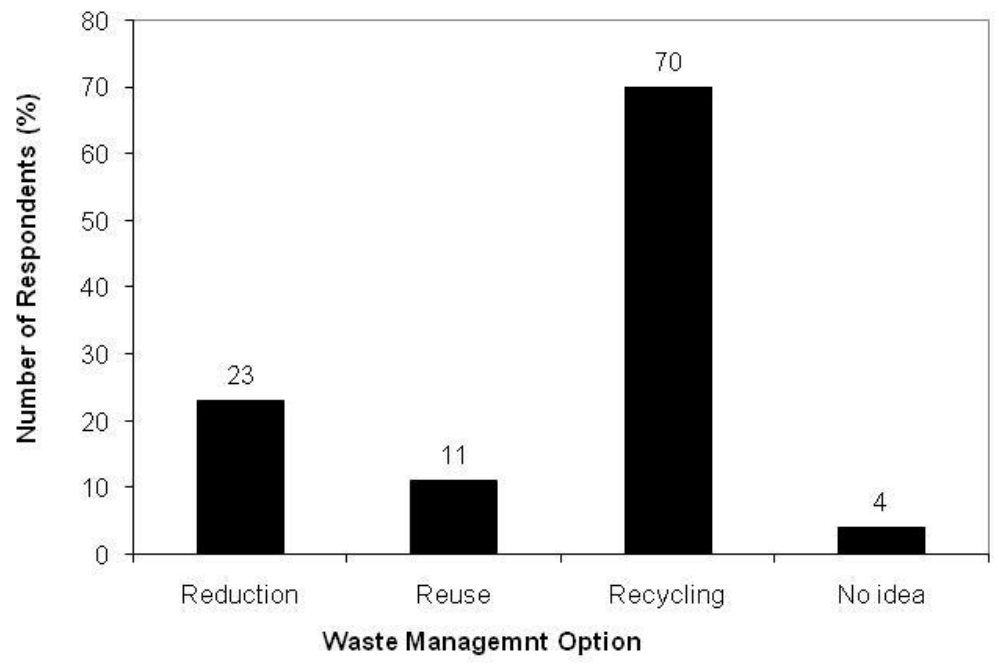

Figure 1: Preference on waste management

\section{Environmental Concern}

Community had different ideas on the effect of waste on living beings and the environment. However, majority $(74 \%)$ of them said that respiratory problems may occur due to mismanagement of waste (Figure 2).

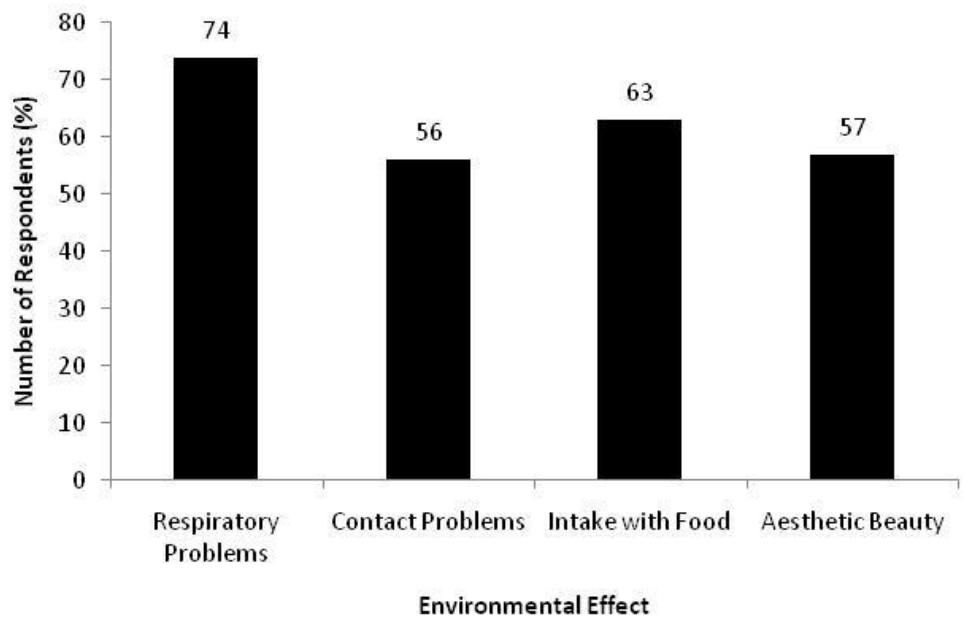

Figure 2: Effect of waste on living beings and the environment 


\section{Present Waste Disposal Technologies}

Majority (66\%) of the respondents has noticed the installed compost bins in the faculty; however, 59\% of them had not been known the function of the compost bins (Figure 3).

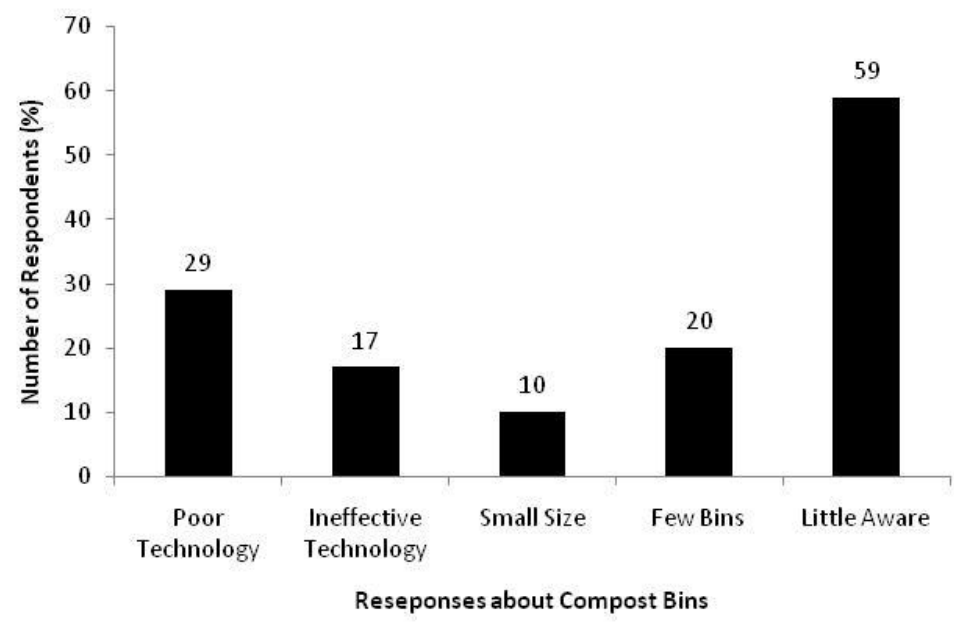

Figure 3: Views on compost bins installed in the faculty

The open dumping and the burning of collected waste are the major waste disposal methods practiced in the Faculty (Figure 4). The cheapest and the most common option being practiced in most places in the country are open dumping and burning of wastes. The administration of the Faculty has taken steps in various occasions to streamline the waste management by introducing various technologies such as compost bins, separation of wastes, etc. However, the study showed that the most of the persons do not pay attention for the proper practicing of those technologies. The study team also observed that the most of the compost bins have been neglected or inappropriately used (Figure 5).

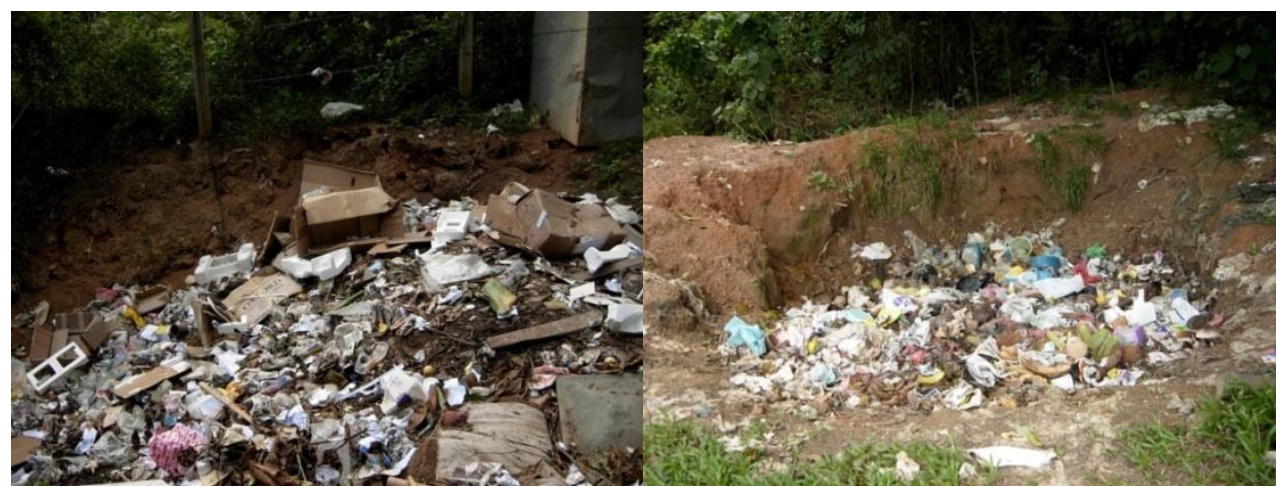




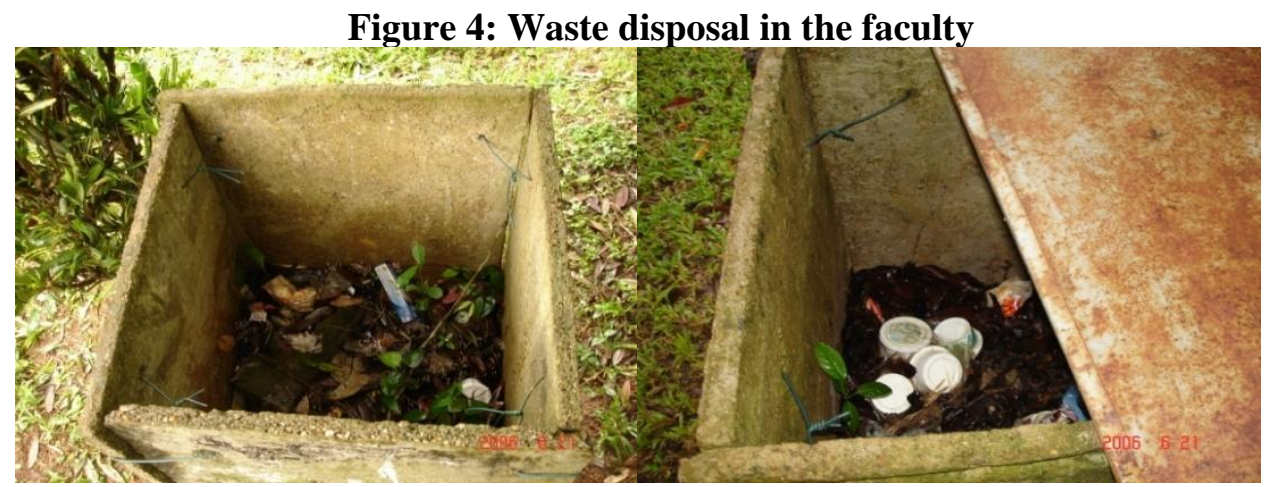

Figure 5: Inappropriately used compost bins

The waste collection and disposal activities are totally practiced by a private company. Their main duty is to clean the surrounding of buildings including students' hostels. Therefore, the attention for waste disposal is minimal and their duty ends when they disposed collected wastes to a place where people could not see. There are ample areas in the Faculty where waste can be dumped in the out of the vicinity of the people. The working efficiency and their education level are also poor and it further will affect for the waste disposal system. To overcome above ineffectiveness with respect to waste disposal, it is essential to make a mechanism to monitor the activities of sanitary workers and the responsibility of waste management should also be included to the sanitary company work profile.

\section{Views of Respondents on Waste Composition}

The majority of respondents think that the highest portion of the waste could be polythene. Polythene would be more harmful than other wastes if they are not properly managed. The respondents said that polythene could be the most abundant waste in the Faculty. However, the amount of polythene generation in the Faculty is about less than $0.20 \%$ while food waste is about $93 \%$ (Wijetunga and Liyanaarachchiet al, 2010). The details of respondents' views on waste composition are displayed in Figure 6. The average percentage of plastics and polythene in municipal solid waste in Sri Lanka is about 5.91 (Premachandra, 2006). However, the plastics and polythene content of waste in the Faculty of Agriculture is much less than average values of Sri Lanka and it has been reported as 1.12 (Wijetunga and Liyanaarachchi, 2010).

\section{Waste Separation}

The administration has introduced a waste separation system in few places, aiming to further enhance the waste disposal in the faculty. However, it was also not properly practiced and monitored. Majority (86\%) of the respondents had known about introduced waste separation system. Almost all parties in any institute should 
know about waste separation systems they practice if it is functioning properly. If 1 or $2 \%$ of persons in the institutes do not know or practice the waste separation process, it will badly affect the effectiveness of the system.

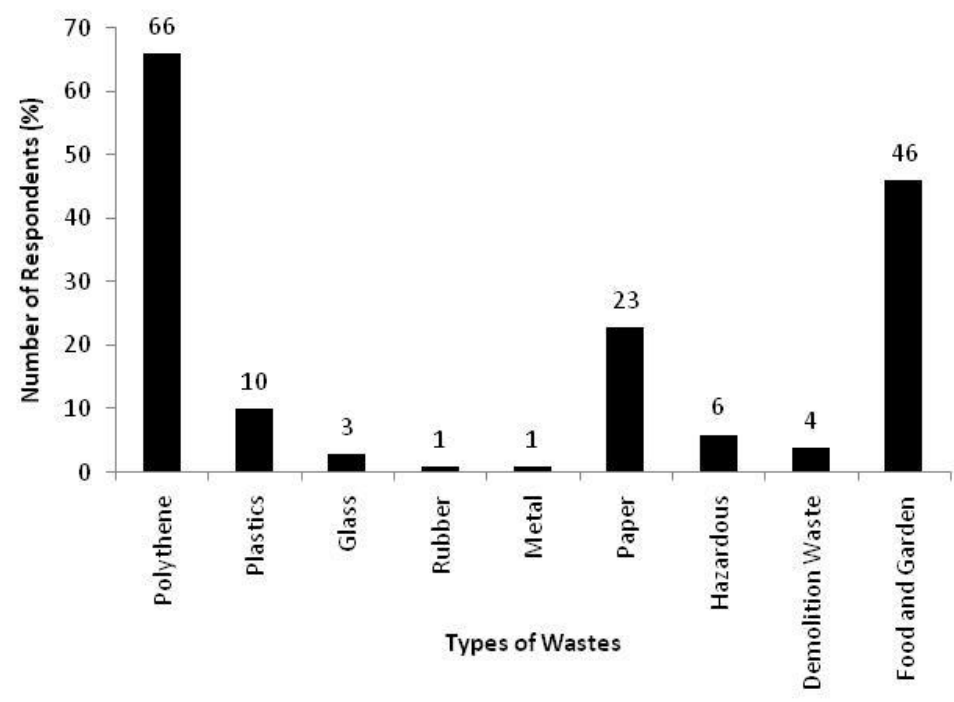

Figure 6: Proportion of different waste according to the community views

Out of those who were not practicing waste separation within the faculty, $50 \%$ had not known about the waste separation system. Fourteen percent had not have time to think and others may think that there is no use of waste separation in the Faculty. Further $22 \%$ said that they do not have interest on such a waste management system. These results revealed that the unawareness of program of waste management among the persons and the inadequacy of the present waste collection system. 


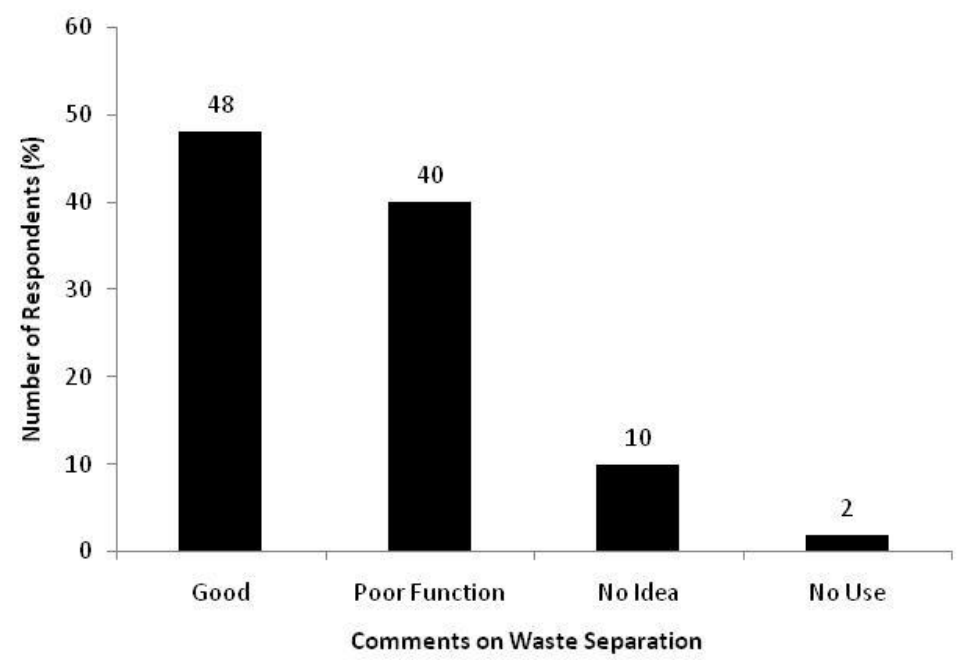

Figure 7: Attitudes on waste separation

\section{View on Participation for Waste Management}

According the survey conducted, $89 \%$ of respondents had the positive attitudes for the participation of waste management in the Faculty towards sustainability. The rest of respondents (11\%) had different ideas about waste management. Among them, 50\% did not have clear idea about the waste management while $37 \%$ argued that even though Faculty runs a proper waste management system they will not have enough time to engage with it. Further $13 \%$ do not have any interest to participate in waste management.

The greater part of respondents (66\%) did not know what happen to waste after disposal. This further indicated that their poor awareness of the waste management system. Thirty seven percent of respondents who known the fate of waste at final disposal said the waste is burnt at the final disposal site (Figure 8). It is common to see the openly dump waste were burnt frequently in the Faculty even though it is not environmentally sound method. 


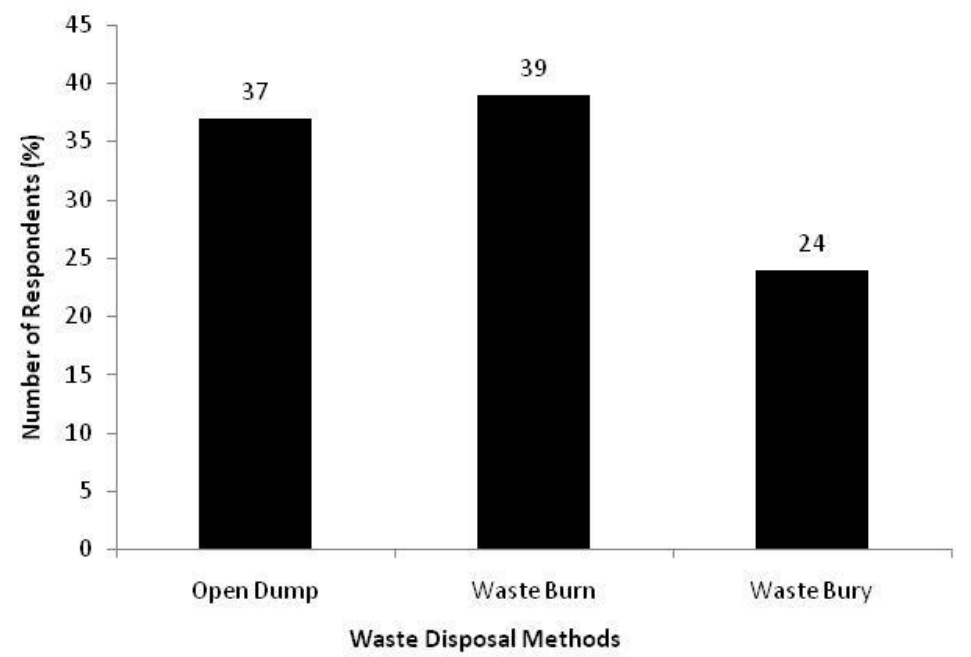

Figure 8: Respondents views on waste management

\section{Problems in Waste Management}

Most of the respondents made several suggestions to improve the waste management system in the Faculty. The majority agreed on that the lack of cooperation and participation are the major constrains $(69 \%)$ in waste management. The second highest proportion (44\%) mentioned that the lack of labor as a major constrain. The lack of technology and lack of physical resources were also shown as major constraints in waste management in the Faculty (Figure 9).

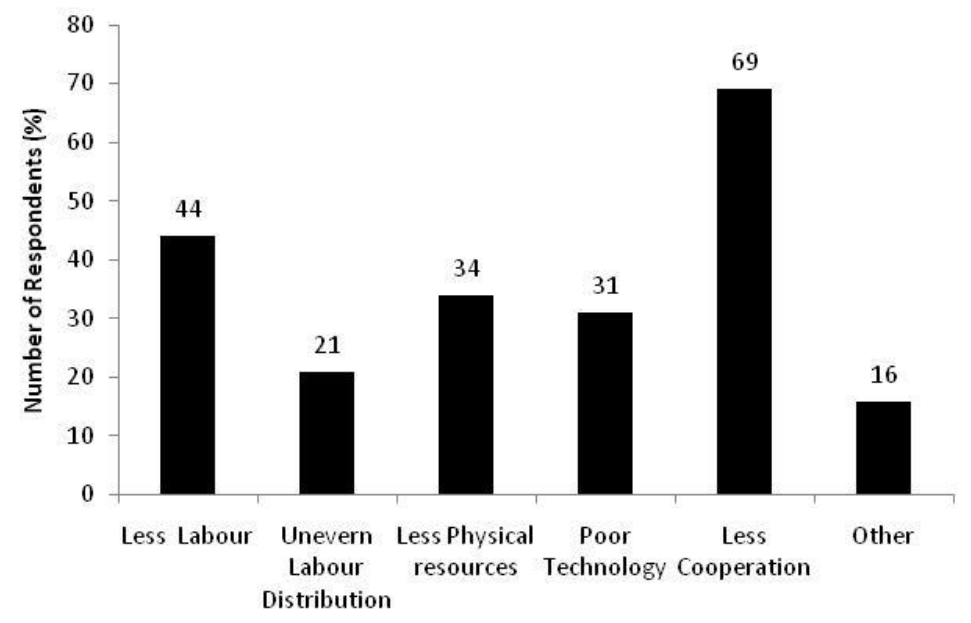

Constrains in Waste Disposal

Figure 9: Major constraints identified by the community 
Majority of the community do not know about Sustainable Waste Management System (SWMS) (51\%). Even though they identified the waste management concept, they did not have any idea about SWMS. The most importantly, the people in the Faculty are not in position to consider the management of their waste. It was evident that the large extent of land (108 acre) in the Faculty still provides ample opportunity of free dumping of garbage. But it was clearly stated by the community in the informal discussions, environmental deterioration had already begun in certain places in the Faculty. Faculty is maintaining a man made Mahogany forest and a small area of secondary natural forest. Even though this land area is small as far as natural forest ecosystems are concerned, it is a habitat for wild animals and birds.

According to the information from senior workers of the Faculty of Agriculture, particularly from faculty farm, they have observed that there are certain severe environmental changes due to improper dumping of waste to the natural ecosystem. It is clearly stated that in the informal discussions, the open dumping of waste hugely increase the street dog population and it has caused unsafe situation of the health of the community in the Faculty, further it results the unsanitary conditions and the spreading of certain epidemic diseases such as tick fever. At previous occasions, some students' hostel have completely been vacated and students have been evacuated to avoid the spreading the ticks. This was a clear incident where inappropriate waste dumping could cause severe management problems of the Faculty, which ultimately cost much money as well.

Most of the respondents $(87 \%)$ showed their dissatisfaction over waste disposal practices. They further argued that administration do not pay enough attention for the waste management. However the community greatly expressed that educated people in the Faculty has a huge potential for implementation of a Sustainable Integrated Waste Management System (81\%). They were also highlighted the other potentials such as technology and manpower within the Faculty (Figure 10) as an advantages. 


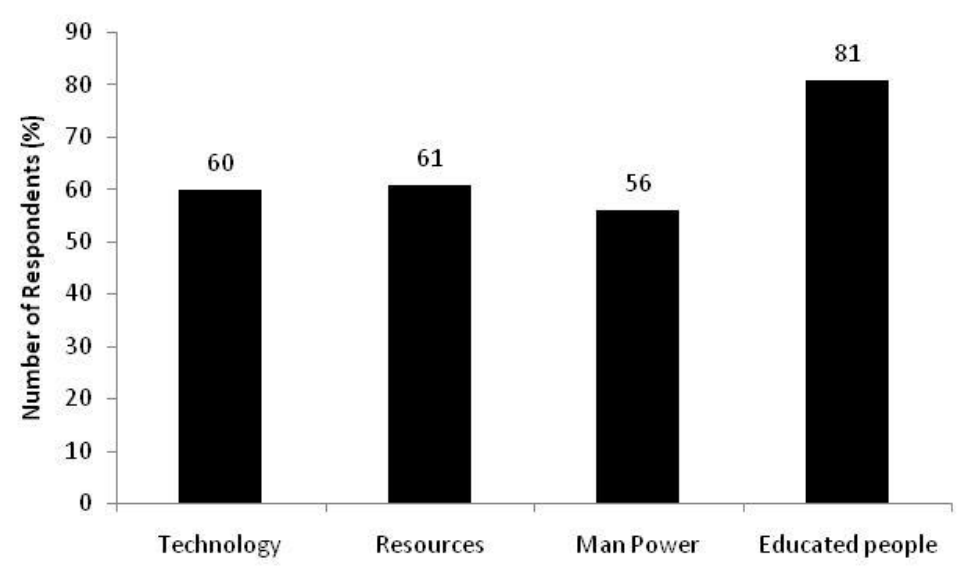

Potentials of Waste Management

Figure 10: Potentials for waste management

Apart from solid waste, $71 \%$ had noticed wastewater sources within the Faculty; however, only $49 \%$ of them had seen proper wastewater treatment plants through TV, Newspaper, and real situation. Eighty six percent can identify the wastewater. Majority of them (87\%) recognize wastewater by color and $32 \%$ identify by color, odor and other physical properties. Around $70 \%$ of them confirmed that wastewater could be identified by the chemical analysis. These information indicate that the most of the community in the Faculty are well aware the water pollution and wastewater issues.

Resources utilization, especially energy utilization is directly related to environmental pollution. It is essential to pay attention on energy utilizations as well as energy conservation when the management of waste is performed. Environmental degradation by various human activities causes global warming which results climatic change. The burning of fossil fuels for generation of energy is a major cause of environmental degradation. Energy shortages and energy prices are burning issues in Sri Lanka. The efficient utilization of other resources such as water, paper, etc is also more important in reduction of waste generation. The attitudes of community towards energy conservation and other resource utilization are also more important as waste management issues. Therefore, the information on these was also gathered during the later part of the study.

Majority of the respondents agreed that there is a correlation between energy conservation and environmental pollution. Ninety three percent of respondents concerned about energy conservation. Out of those, $24 \%$ respondents use sunlight as far as possible for light and drying of cloths while $28 \%$ use energy efficient electrical instruments. Forty eight percent of respondents commented that they 
helped to conserve energy by switching off the bulbs and electrical instruments when they are not in use in the faculty and home. Most of the members (70\%) use energy saving bulbs at their homes. Many believed that the current energy conservation practices in the Faculty are not effective to conserve energy wastages. Over ten places of water wastages had been observed by $21 \%$ of respondents while $31 \%$ revealed that they noticed $2-5$ places. It indicated that there are places where water is wasting due to less priority of maintenance of water distribution systems.

\section{Conclusions}

In this study, it was found that the faculty administration has taken several steps to enhance the waste management in the faculty; however, further commitment of the administration is required for the proper waste disposal in the faculty. The majority of the people in the faculty fairly know the consequences arising from the uncontrolled disposal of waste. Their knowledge on waste management technologies and related issues are satisfactory, even though they do not like to spend a very little time on waste management activities such as waste separation, to enhance the waste management system in the faculty.

Further, it was found that even though the most of the people in the faculty are fairly educated, the strong attitudinal changes are required for the functioning of a proper sustainable integrated waste management system that could be accepted by the all stakeholders of the faculty. Further exploration of currently available resources is vital and commitment of the cleaning service workers (private company that responsible for faculty cleaning services) as well as the active participation of the students, academic and non-academic staffs are greatly important. The people in the Faculty like to cooperate and participate for a proper waste management system. Therefore, their involvement should be encouraged for the development and implementation of waste management system in the Faculty. The views and attitudes of the stake holders are very important for the proper function of waste management systems in any institute and therefore, before implementation of waste management system, stakeholders' views should be taken and their attitudinal changes should also be made where necessary.

\section{Acknowledgement}

The financial support by National Science Foundation (RG/2006/EPSD/02) of Sri Lanka to carry out this study and support for data collection by N.Liyanaarachchi is greatly appreciated. 


\section{References}

Forbes M., W. Peter, F. Marina and H. Peter H (2001). "Integrated solid waste management: a life cycle inventory" Blackwell Science Ltd, Malden, USA.

Wijetunga, S. and N. Liyanaarachchi (2010). "Influence of undergraduates activities on the waste composition and generation rates in a residential university - case study", $15^{\text {th }}$ International Forestry and Environment Symposium, University of Sri Jayewardenepura, Sri Lanka.

Visvanathan, C. (2006). "Domestic solid waste management in South Asia" 3 R South Asia Expert Workshop, Kathmandu, Nepal.

Perera, K. L. S. (2003). "An overview of the issue of solid waste management in Sri Lanka" Proceedings of the $3^{\text {rd }}$ International Conference on Environment and Health, Chennai, India, 15-17.

Premachandra, H. S. (2006). "Household waste composting and MSW recycling in Sri Lanka" Asia 3R conference, Tokyo (available from: www.env.go.jp/recycle/3r/en/asia/02 03-3/08.pdf [Accessed 3 January 2011]. 